\title{
Investigation of Proteomic Responses and Anticancer Activities of an Isolated Strain of Cordyceps sinensis Under Different Nutritional Fermentation Conditions
}

\section{Lee ST, Huang MY and Wu TF* \\ Department of Biotechnology, Southern Taiwan University of Science and Technology, Taiwan}

*Corresponding author: Ting-Feng Wu, Department of Biotechnology, Southern Taiwan University of Science and Technology, 1 Nan-Tai Street, YungKang District, Tainan, Taiwan 701, Email: wutingfe@stust.edu.tw

\section{Research Article \\ Volume 4 Issue 1}

Received Date: January 16, 2019

Published Date: January 28, 2019

DOI: $10.23880 /$ oajmb-16000137

\section{Abstract}

Cordyceps sinensis is a fungal parasite on the larvae of Lepidoptera and has been used as a tonic herb in the traditional Chinese medicines. The fruit bodies of $C$. sinensis are limited because of the difficulty in cultivation. The mycelia produced by the fermentation have already become the best substitute for $C$. sinensis. The fungus strain called G308-1 strain used in this study was isolated from the fruit bodies of $C$. sinensis in Yunan Province of People Republic of China. From the comparisons of rDNA sequences against Gene Bank, the G308-1 strain was identified as Paecilomyces farinosus. In this study, the proteomic profiles of the G308-1 strain grown in the different liquid media containing glucose, sucrose, maltose or lactose as the sole carbon source were established using two-dimensional gel electrophoreses. The proteomes of the mycelia in the glucose media were compared respectively to those in the other three media. The comparative results showed that two, five and seventeen protein spots were repressed respectively in the mycelia in the sucrose, maltose and lactose media while six, three and eight protein spots were induced respectively. In order to explore the correlation between the proteomes and the anticancer activities of the mycelia, the water or ethanol extracts of the G3081 strain cultivated in various media were examined for their abilities to suppress the HepG2, Du145, Hela and MCF-7 cells. The anticancer results demonstrated that the water extracts showed the selectivity to Hela and Du 145 cells and the high concentrations of the water extracts made from the mycelia in the lactose media had better suppressive effects on the HepG2 cells. Essentially the ethanol extracts prepared from the mycelia in the lactose media showed much better inhibitory activities to each cell line than those from the other three media. The above results suggested the anticancer results might vary with the proteome profile changes which probably resulted in the production of a different array of bio-products in the mycelia under the different nutritional conditions.

Keywords: Cordyceps Sinensis; Paecilomyces Farinosus; Proteomics; Proteome two-Dimensional Gel Electrophoresis; Anti-Cancer 


\section{Open Access Journal of Microbiology \& Biotechnology}

\section{Introduction}

Cordyceps sinensis of the clavipitaceae family is a medicinal fungus of traditional Chinese medicine. It possesses many pharmacological activities, including regulating the immune system [1-4], hypotensive effect [5], inhibiting the platelet aggregation [6], stimulating the hepatic energy metabolism [7], improving the renal disorder [8], antioxidant activities [9,10] and modulating the apoptosis homeostasis [11]. Furthermore, sterols isolated from Cordyceps sinensis were shown to be a great inhibitor to the proliferation of K562, Jukart, WM-1341, HL-60 and RPMI-8226 tumor cell lines [12]. In addition, Yang et al. (2002) [13] reported that H1-A extracted from Cordyceps sinensis can suppress the proliferation of human mesangial cell and may evoke the apoptosis by down-regulating the tyrosine phosphorylation of Bcl-2 and Bcl-XL.

The fruit bodies of Cordyceps sinensis are rare and expensive. Therefore, the fermentation-grown mycelia with the pharmacological activities draw many attentions. However, different fermentation conditions may have the different impacts on the therapeutic activities of Cordyceps sinensis. The metabolites synthesized in Cordyceps sinensis may be altered by changing the nutritional fermentation conditions due to the differential protein expressions. Nowadays no any work has been focused on investigating the globe protein expression in Cordyceps sinensis influenced by the nutritional fermentation condition.

Two-dimensional (2D) gel electrophoresis can visualize hundreds of proteins at a time, which coupled with mass spectrometry results in their identification. This technique has been applied to examine the global changes in the proteome map in Saccharomyces cerevisiae in response to the fermentation stress $[14,15]$ as well as environmental stimuli such as cadmium [16], lithium [17], $\mathrm{H}_{2} \mathrm{O}_{2}$ [18], or sorbic acid [19] and to the metabolic engineering in E. coli [20].

In this study, different liquid media containing various carbon sources were used for the cultivation of a strain of Cordyceps sinensis which was isolated in Yunnan province of People Republic of China and called G308-1 strain. The extracts of G308-1 strain grown in different liquid media were examined for their anticancer activities. Besides, the proteome maps of mycelia collected from the different media were compared to figure out the impact of various carbon sources on the protein expression.

\section{Materials and Methods}

\section{Cultivation of the G308-1 Strain}

The fungus strain used in this study was provided by Safe Protecta Technology Co., Ltd, Tainan, Taiwan and named as G308-1 strain. The voucher specimens were deposited at Culture Collection Laboratory of Department of Biotechnology, Southern Taiwan University of Technology, Tainan, Taiwan. The G308-1 strain was isolated from the fruit bodies of $C$. sinensis grown at DehChin city of Yunnan province, People Republic of China. The G308-1 strain was cultivated in $500 \mathrm{ml}$ shake flask containing $100 \mathrm{ml}$ of liquid media [0.5 \% (w/v) yeast extract, $0.05 \%$ (w/v) $\mathrm{MgSO}_{4}, 0.03 \%$ (w/v) $\mathrm{KH}_{2} \mathrm{PO}_{4}, 0.2 \%$ (w/v) $\mathrm{Na}_{2} \mathrm{HPO}_{4}$ and $3 \%(\mathrm{w} / \mathrm{v}$ ) each of various carbon sources (glucose, maltose, sucrose or lactose)] with 250 rpm at $\mathrm{pH} 7.0$ and $17^{\circ} \mathrm{C}$ for 7 days till the exponential phase reached.

\section{Preparation of the Extract from the G308-1 Strain}

The water extracts of G308-1 strain were prepared by incubating the mycelia with $60^{\circ} \mathrm{C}$ water for 2 hours at the ratio of 1 to $10(\mathrm{w} / \mathrm{v})$. Then the suspension was centrifuged at 3,000 $\times g$ and the supernatant was passed through a $0.2-\mu \mathrm{m}$ pore size filter (Millex GP Carrigtwohill Co., Cork, Ireland). The filtrate was evaporated to onetenth of the original volume. The ethanol extracts of G308-1 were prepared as in preparation of the water extract except that the mycelia were incubated with $95 \%$ of ethanol for 16 hour at $25^{\circ} \mathrm{C}$ at the ratio of 1 to $10(\mathrm{w} / \mathrm{v})$.

3-(4,5-dimethylthiazol-2-yl)-2,5-diphenyltetrazolium bromide (MTT) assay: Various concentrations of the water or ethanol extracts were added to a 96-well plate already loaded with HepG2, Du145, Hela or MCF-7 cells per well. After treatment for 72 hours, $20 \mu \mathrm{l}$ of MTT solution (Merck, Damstadt, German) (5 mg/ml PBS) was added to each well and the plate was incubated at $37^{\circ} \mathrm{C}$ for 4 hours. After medium removal, $200 \mu$ of DMSO was added to each well and the plate was gently shaken for 5 minutes. The absorbance was determined at $540 \mathrm{~nm}$. Triplicate wells were applied to each concentration for 72 hours as shown in Figures 4 and 5. The untreated or ethanol-treated cells were employed as the control.

\section{Isolation of Genomic DNA and Polymerase Chain Reaction}

The genomic DNA of G308-1 strain was isolated from the mycelia according to the Chelex method [21]. Briefly, an 
aliquot of about $300 \mu \mathrm{l}$ Chelex 100 (Bio-Rad 36897, 50100 mesh, Richmond, CA) was deposited in a sterile Eppendorff tube containing $500 \mu \mathrm{l}$ of sterile water. Then small amount of the mycelia was transferred into the Eppendorff tube, crashed the mixture by Eppendorff stick and incubated at $95^{\circ} \mathrm{C}$ for 10 minutes. The crashed solution was centrifuged at $13,000 \mathrm{rpm}$ for 2 minutes. The supernatant was collected and diluted with sterile water by 100 times. These samples could be subjected to PCR.

The rDNA (nuclear ribosomal DNA) regions of the genome including 18S, ITS (internal transcribed spacers), 5.8S and 25S are highly conserved among the fungi. Thus their sequences are usually subjected to phylogenetic analyses. Five pairs of primers [21] were used to perform PCR amplification and sequencing of the rDNA regions in G308-1 strain. As illustrated in Figure 1A, the primers ITS1 (5'-TCCGTAGGTGAACCTGCGG)/ ITS4 (5'TCCTCCGCTTATT GATATGC) were used for the amplification of ITS region while NS1 (5'GTAGTCATATGCTTGTCTC)/NS2 (5'GGCTGCTGGCACCAGACTTGC), NS3 (5'GCAAGTCTGGTGCCAGCAGCC)/NS4 CTTCCGTCAATTCCTTTAAG) and NS5 (5'AACTTAAAGGAATTGACGGAAG)/NS8 (5'TCCGCAGGTTCACCTACGGA) were used for the amplification of 18S rDNA and NL1 (5'GCATATCAATAAGCGGAGGAAAAG)/NL4 (5'CCAGGCACAAAGTTCTGCC) were used for the amplification of $25 \mathrm{~S}$ rDNA region.

The PCR reaction was performed in a mixture containing $25 \mathrm{ng}$ of DNA template, $10 \mu \mathrm{g}$ of primer, $2 \mu \mathrm{l}$ of $25 \mathrm{mM} \mathrm{dNTP}$, and $5 \mu \mathrm{l}$ of $10 \mathrm{x}$ reaction buffer $(100 \mathrm{mM}$ Tris- $\mathrm{HCl}, \mathrm{pH} 9.0,500 \mathrm{mM} \mathrm{KCl}, 15 \mathrm{mM} \mathrm{MgCl}_{2}, 1 \%$ Triton X$100)$ and $0.2 \mu \mathrm{l}$ of Taq polymerase ( $5 \mathrm{U} / \mu \mathrm{l})$. The thermal program for PCR amplifications consisted of a single denaturing step for 2 minutes at $95^{\circ} \mathrm{C}$, followed by 35 cycles of denaturing at $95^{\circ} \mathrm{C}$ for 30 seconds, annealing at $47^{\circ} \mathrm{C} \sim 52^{\circ} \mathrm{C}$ for 30 seconds and elongating at $72^{\circ} \mathrm{C}$ for 30 seconds. The reaction was completed with a single cycle of $72^{\circ} \mathrm{C}$ for 7 minutes. The PCR products were separated by electrophoresis and these rDNAs were sequenced by Applied Biosystems Ltd. Co. (Taipei, Taiwan). The resulting DNA sequence were analyzed using the BLAST software and MEGA 3 software based on the nucleotide sequences available in the GeneBank database.

\section{Preparation of Protein Lysate}

After fermentation, the mycelia were collected by centrifugation at 3,900 $\times \mathrm{g}$ from the liquid media and then dried in Speed Vac (ThermoSavant, Milford, MA) for 5 minutes. $0.2 \mathrm{~g}$ of pelleted mycelia were ground in liquid nitrogen and lysed in $1 \mathrm{ml}$ lysis buffer [7M urea, $2 \mathrm{M}$ thiourea, $4 \%(\mathrm{v} / \mathrm{v}$ ) CHAPS, $100 \mathrm{mM}$ dithiothreitol, $40 \mathrm{mM}$ Tris pH 10, $20 \mu \mathrm{l}$ Roche Complete mini protease inhibitor cocktail per $500 \mu \mathrm{l}$ buffer] at room temperature for 1 hour. Samples were then centrifuged at $18,300 \times \mathrm{g}$ for 20 minutes. The supernatant was collected and centrifuged again at $349,000 \times$ g for 3 hours at $15^{\circ} \mathrm{C}$ in Optima L- $90 \mathrm{~K}$ ultracentrifuge (Beckman Coulter, Fullerton, CA). After centrifugation, the supernatant was cleaned with 2D clean kit (Amersham-Pharmacia Biotech Inc., Piscataway, NJ) according to the manufacture's suggestion and the protein pellet was dissolved in rehydration buffer [7M urea, $2 \mathrm{M}$ thiourea, 4\% (v/v) CHAPS, 26mM dithiothreitol, 0.5\% (v/v) IPG buffer and trace amount of bromophenol blue] and stored at $-80^{\circ} \mathrm{C}$ until use. The protein concentration was measured using a DC protein assay kit (BioRad, Hercules, CA).

\section{Two-Dimensional Gel Electrophoresis (2-DE)}

The immobibline dry strips (Pharmacia pI 4-7L, $11 \mathrm{~cm}$ ) were rehydrated at $20^{\circ} \mathrm{C}$ for 16 hours with $200 \mu \mathrm{l}$ rehydration buffer containing $60 \mu \mathrm{g}$ of protein. The proteins were then focused at $200 \mathrm{~V}, 500 \mathrm{~V}, 1000 \mathrm{~V}, 5000 \mathrm{~V}$ and $8000 \mathrm{~V}$ with a total of 43,700 voltage-hours. After isoelectric focusing, the gel strips were incubated in dithiothreitol equilibration buffer [0.05M Tris pH 8.8,6M urea, $30 \%(\mathrm{v} / \mathrm{v})$ glycerol, $2 \%(\mathrm{w} / \mathrm{v})$ SDS, and $1 \%(\mathrm{w} / \mathrm{v})$ dithiothreitol] for $15 \mathrm{~min}$ and then in iodoacetamide equilibration buffer $[0.05 \mathrm{M}$ Tris $\mathrm{pH} 8.8,6 \mathrm{M}$ urea, $30 \%$ (v/v) glycerol, 2\% (w/v) SDS, and $2.5 \%$ (w/v) iodoacetamide] for a further $15 \mathrm{~min}$. The equilibrated gels were loaded onto the top of $12.5 \%$ acrylamide gel and sealed with $0.5 \%$ agarose. The proteins were separated until bromophenol blue reaches the bottom of the gel.

\section{Silver Staining}

Silver staining were performed according to the protocol described by Yan et al. In brief, the gels were fixed in fixation solution (ethanol/water/acetic acid, $4 / 5 / 1, \mathrm{v} / \mathrm{v}$ ) after electrophoresis and soaked in sensitizing solutions $[30 \%(\mathrm{v} / \mathrm{v})$ ethanol, $6.8 \%(\mathrm{w} / \mathrm{v})$ sodium acetate, $0.2 \%(\mathrm{w} / \mathrm{v})$ sodium thiosulphate and $0.125 \%(\mathrm{v} / \mathrm{v})$ glutardialdehyde] for 30 minutes. After sensitization, the gels were washed, incubated in silver nitrate solutions $[0.25 \%(\mathrm{w} / \mathrm{v})$ silver nitrate and 0.0148 $\%$ (v/v) formaldehyde] for 20 min and then developed with the developing solution $[2.5 \%(\mathrm{w} / \mathrm{v})$ sodium carbonate and $0.0074 \%(\mathrm{v} / \mathrm{v})$ formaldehyde]. 


\section{Open Access Journal of Microbiology \& Biotechnology}

\section{Image Analysis}

The proteome profiles of the G308-1 strain were analyzed by PDQuest (BioRad) software to search for differentially expressed proteins. Six replica well-focused gels collected from three batches of the mycelia in each liquid medium were compared. Differentially expressed spots found by computer analysis were further examined by visualization. The intensity of the spot was computed and normalized as a percentage of the total intensity of all spots in a gel and analyzed with student's t-test (Pharm PCS Version 4.2, Springer-Verlag, New York, USA). In all cases, statistical variance of the spot intensity ratio within 95\% (Student's t-test; $p<0.05$ ) was considered to be significantly different.

\section{Liquid Chromatography-Tandem Spectrometry (LC-MS/MS)}

Electrospray ionization (ESI) tandem mass spectrometry was performed as described previously $[22,23]$ using a ThermoFinnigan LCQ Deca ion trap mass spectrometer interfaced with an Agilent 1100 HPLC system. The spots of interest were excised from the gel and digested with modified trypsin (AmershamPharmacia Biotech Inc., Piscataway, NJ) as described previously [21]. The digested peptides were separated in an Agilent ZORBAX 300SB-C18 column using a mobile phase of solution A $(0.1 \%$ formic acid in water) and solution B $(0.085 \%$ formic acid in acetonitrile). The peptides eluted from the HPLC were introduced on-line to the ESI source and the spectra were acquired as successive sets of three scan modes (MS, Zoom and MS/MS scans). The acquired collision-induced dissociation spectra were interpreted using TurboSequest software (ThermoFinnigan, San Jose, CA) which matches predicted tandem mass spectra against non-redundant protein database.

\section{Results}

\section{Determination of the phylogenetic relationship of the G308-1 strain to Cordyceps sinensis}

Since the G308-1 strain was isolated from the fruit bodies (teleomorph; sexual stage) of $C$. sinensis, the G3081 strain cultivated in the liquid media might be the anamorph (asexual stage). In order to demonstrate that the G308-1 strain was the anamorph, the mycelia were authenticated using the conventional fungal classification methods by Dr. Roland Kirschner in Botany Institute University of Frankfurt, German. The classification results suggested that the G308 strain belonged to Paecilomyces farinosus (data not shown). To further confirm this identification, various regions of rDNA of the G308-1 strain including the internal transcribed spacers (ITS) were amplified with the polymerase chain reaction. As shown in Figure 1A, five pairs of PCR primers (NL1\&NL4, ITS1\&ITS4, NS1\&NS2, NS3\&NS4 and NS5\&NS8) were utilized to amplify the rDNA regions as described by Chen et al. (2001)[22]. The PCR fragments with the expected sizes could be amplified from rDNA using each primer pair (Figure 1B, lanes 2-6). The nucleotide sequence of each PCR fragment was compared against GeneBank using the BLAST software. The comparative results showed that each nucleotide sequence was nearly $100 \%$ identical to that of Paecilomyces farinosus.

In order to further analyze the link of the G308-1 strain to $P$. farinosus, the distance values of ITS sequences between $P$. farinosus and its allies were estimated using MEGA 3 software and presented in Table 1 . The zero distance value between the G308-1 strain and P. farinosus indicated that the G308-1 strain should belong to $P$. farinosus. In addition, the phylogenetic tree was reconstructed from the distance values using the neighbor-joining (JN) method to confirm the relationship between the G308-1 strain and $P$. farinosus. As demonstrated in Figure 1C, the G308-1 strain and $P$. farinosus were combined into a single clade.

A.

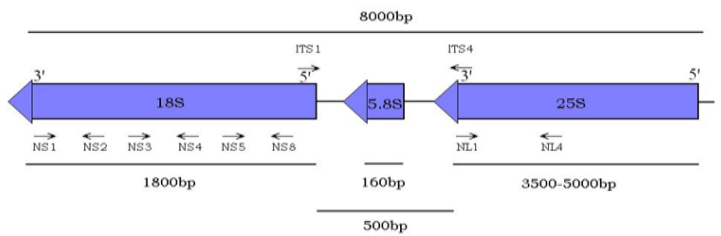

B.

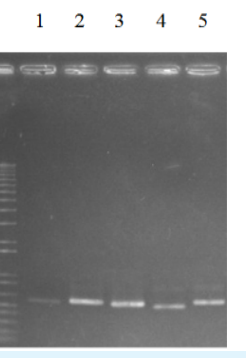

C.

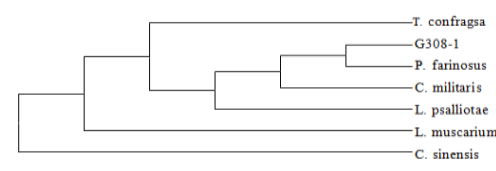

Figure 1: The molecular identification of Paecilomyces farinosus using rDNA regions. (A) The locations of the primers used in the polymerase chain reactions. (B) The PCR products amplified from the genomes of $P$. farinosus using the above primers. Lane 1, PCR with NL1 and NL4; lane 2, ITS1 and ITS4; lane 3, NS1 and NS2; lane 4, NS3 and NS4; lane 5, NS5 and NS8. (C) Molecular phlyogenetic tree inferred from the ITS of G308-1 strain and its allies. 
Open Access Journal of Microbiology \& Biotechnology

\begin{tabular}{|c|c|c|c|c|c|c|c|}
\hline & G308-1 & P. farinosus & T. confragosa & V. psalliotae & L. muscarium & C. militaris & C. sinensis \\
\hline G308-1 & - & 0 & 0.04 & 0.04 & 0.04 & 0.07 & 0.54 \\
\hline P. farinosus & & - & 0.04 & 0.04 & 0.04 & 0.07 & 0.54 \\
\hline T. confragosa & & & - & 0.03 & 0 & 0.06 & 0.49 \\
\hline V.psalliotae & & & & - & 0.03 & 0.07 & 0.53 \\
\hline L. muscarium & & & & & - & 0.06 & 0.49 \\
\hline C. militaris & & & & & & - & 0.55 \\
\hline C. sinensis & & & & & & & - \\
\hline
\end{tabular}

Table 1: Distance values between the G308-1 and its allies.

\section{The Proteome Profile Changes of the G308-1 Strain Grown Under the Different Nutritional Media}

Upon exposure to a specific carbon source, cells adopt a corresponding metabolic pathway by adjusting the proteome profiles to assimilate the carbon source for the energy. In order to evaluate the proteome profile changes in response to various carbon sources, two-dimensional gel electrophoreses (2-DE) were carried out to analyze the proteome profiles of the G308-1 strain grown in the liquid media containing glucose, sucrose, maltose or lactose as the sole carbon source. The proteome profiles of the G308-1 strain grown in the glucose media were compared respectively with those in the other three media. The representative 2-DE maps of the G308-1 strain cultivated under the different nutritional conditions were illustrated in Figure 2. On average each gel resolved up to $\sim 850$ protein spots. To prevent the variation of silver staining, six replica gels were collected from three batches. The differentially expressed protein spots were scored which is higher than 1.5 -fold in magnitude as observed in all six replica gels. Eight, eight and twentyfive differentially expressed proteins were observed respectively in the mycelia derived from the sucrose, maltose and lactose media. Among these differentially expressed protein spots, two, five and seventeen protein spots were repressed respectively in the mycelia grown in the sucrose, maltose and lactose media while six, three and eight protein spots were induced respectively. The total normalized volume (ppm), $p \mathrm{I}$, molecular weight and the statistical result of each protein spot were presented in Tables 2-4.

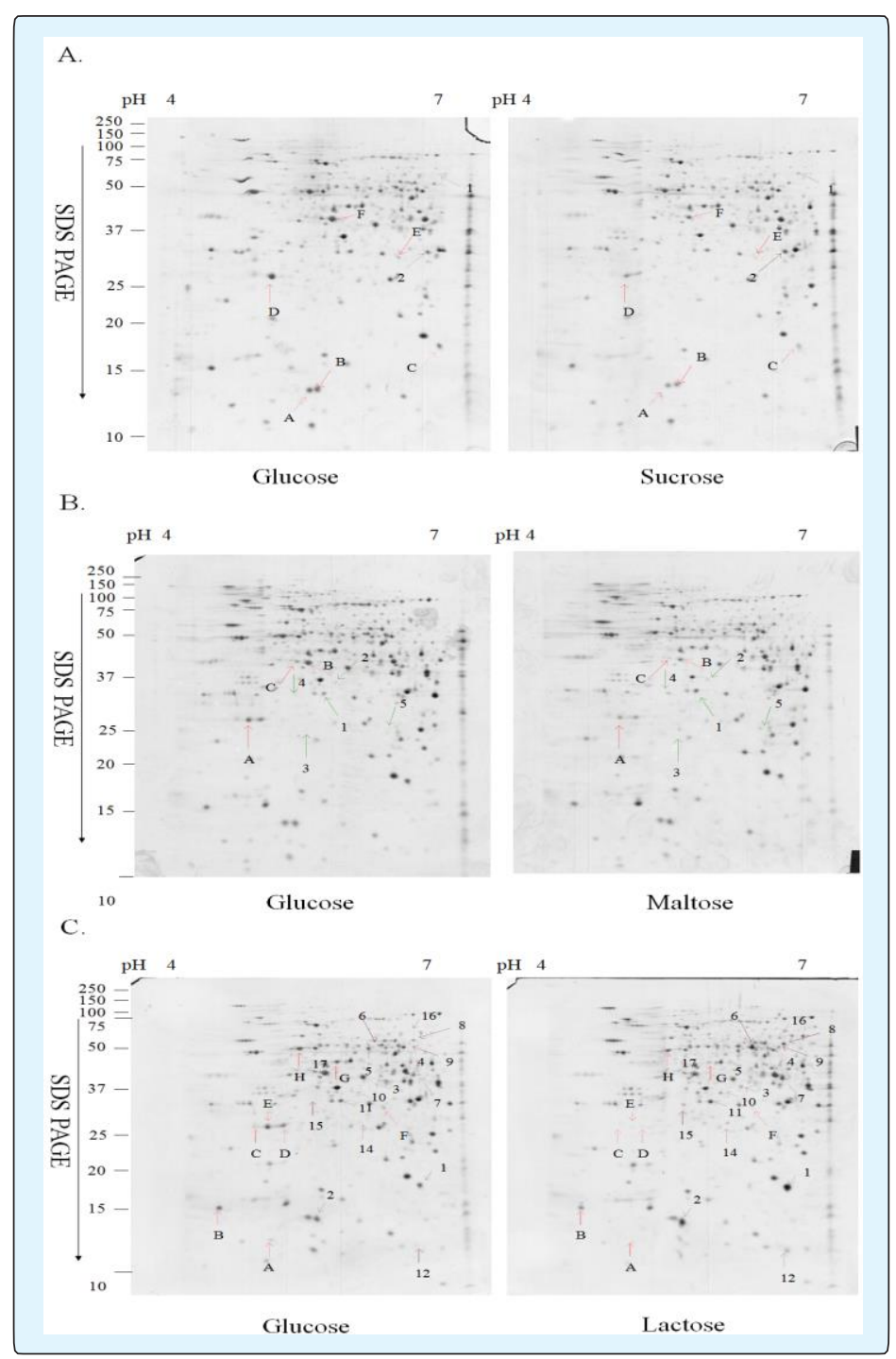

Lee ST, Huang MY and Wu TF. Investigation of Proteomic Responses and Anticancer Activities of an Isolated Strain of Cordyceps sinensis Under Different Copyright@ Lee ST, Huang MY and Wu TF. Nutritional Fermentation Conditions. J Microbiol Biotechnol, 2019, 4(1): 000137. 
Figure 2: The 2-D maps of the mycelia grown in the liquid media containing glucose, sucrose, maltose and lactose. (A) The comparisons of the proteomes of the mycelia cultivated in glucose media to those in sucrose media. (B) The proteomes in glucose media to those in maltose media. (C) The proteomes in glucose media to those in lactose media. The differentially expressed protein spots were indicated by the arrows. The upregulated proteins in sucrose, maltose or lactose media were shown by the Arabic numbers while the down-regulated proteins were indicated by the letters. The figures were the representative gels of six replica gels from three batches.

\begin{tabular}{|c|c|c|c|c|c|}
\hline $\begin{array}{c}\text { Spot } \\
\text { No }\end{array}$ & pI/Mra & $\begin{array}{c}\text { glucose }^{\mathbf{b}} \\
\text { (ppm) }\end{array}$ & $\begin{array}{c}\text { surcose } \\
\text { (ppm) }\end{array}$ & Fold & $\begin{array}{c}\text { P } \\
\text { value }\end{array}$ \\
\hline 1 & $5.98 / 60.7$ & $16.18 \pm 4.03$ & $30.20 \pm 6.02$ & +1.87 & $\mathrm{P}<0.05$ \\
\hline 2 & $5.91 / 32.1$ & $77.5 \pm 27.98$ & $131.16 \pm 19.94$ & +1.69 & $\mathrm{P}<0.05$ \\
\hline A & $5.14 / 13.5$ & $102.93 \pm 6.87$ & $56.32 \pm 6.06$ & -1.83 & $\mathrm{P}<0.01$ \\
\hline B & $5.21 / 13.7$ & $127.92 \pm 12.23$ & $81.97 \pm 6.61$ & -1.56 & $\mathrm{P}<0.05$ \\
\hline C & $5.95 / 17.5$ & $159.33 \pm 38.38$ & $39.15 \pm 8.74$ & -4.07 & $\mathrm{P}<0.05$ \\
\hline D & $4.78 / 26.8$ & $476.72 \pm 159.22$ & $176.6 \pm 61.37$ & -2.7 & $\mathrm{P}<0.05$ \\
\hline E & $5.74 / 30.7$ & $23.33 \pm 8.17$ & $10.27 \pm 3.92$ & -2.27 & $\mathrm{P}<0.05$ \\
\hline F & $5.33 / 44.7$ & $239.03 \pm 61.76$ & $165.83 \pm 66.19$ & -1.44 & $\mathrm{P}<0.01$ \\
\hline
\end{tabular}

${ }^{a}$ pI: isoelectric point; Mr: molecular weight

bLglu: protein spots in the 2D gels of the mycelia grown in glucose media

$c_{+}$: proteins up-regulated in the mycelia grown in sucrose media; -: protein down regulated in the mycelia grown in sucrose media

Table 2: The differentially expressed protein spots between the mycelia grown in glucose and sucrose media.

\begin{tabular}{|c|c|c|c|c|c|}
\hline Spot No & pI/Mr & glucose (ppm) & maltose (ppm) & Fold & P value \\
\hline 1 & $5.45 / 34.0$ & $46.92 \pm 10.45$ & $96.47 \pm 9.7$ & 2.06 & $\mathrm{P}<0.05$ \\
\hline 2 & $5.53 / 34.2$ & $3.03 \pm 0.48$ & $9.8 \pm 1.55$ & 3.23 & $\mathrm{P}<0.01$ \\
\hline 3 & $5.31 / 24.9$ & $0.4 \pm 0.2$ & $12.48 \pm 2$ & 31.2 & $\mathrm{P}<0.01$ \\
\hline 4 & $5.22 / 31.5$ & $1.57 \pm 0.41$ & $32.37 \pm 5.17$ & 20.62 & $\mathrm{P}<0.01$ \\
\hline 5 & $5.85 / 24.4$ & $1.93 \pm 0.7$ & $7.97 \pm 2.45$ & 4.13 & $\mathrm{P}<0.05$ \\
\hline A & $4.78 / 26.8$ & $256.5 \pm 80$ & $56.77 \pm 9.74$ & -4.52 & $\mathrm{P}<0.05$ \\
\hline B & $5.33 / 40.6$ & $160.93 \pm 20.1$ & $84.45 \pm 12.33$ & -1.9 & $\mathrm{P}<0.01$ \\
\hline C & $5.23 / 40.8$ & $34.25 \pm 6.65$ & $11.35 \pm 3.92$ & -3.02 & $\mathrm{P}<0.01$ \\
\hline
\end{tabular}

Table 3: The differentially expressed protein spots between the mycelia grown in glucose and maltose media.

\begin{tabular}{|c|c|c|c|c|c|}
\hline Spot No & $\mathbf{p I} / \mathbf{M r}$ & glucose (ppm) & lactose (ppm) & Fold & P value \\
\hline 1 & $5.95 / 17.5$ & $81.86 \pm 8.34$ & $502.2 \pm 83.9$ & 6.13 & $\mathrm{P}<0.01$ \\
\hline 2 & $5.21 / 13.7$ & $82.3 \pm 10.6$ & $150.7 \pm 30.53$ & 1.83 & $\mathrm{P}<0.05$ \\
\hline 3 & $5.66 / 35.7$ & $0.52 \pm 0.23$ & $27.6 \pm 5.61$ & 53.08 & $\mathrm{P}<0.01$ \\
\hline 4 & $5.89 / 40.9$ & $207.08 \pm 35.02$ & $259.43 \pm 33.63$ & 1.25 & $\mathrm{P}<0.05$ \\
\hline 5 & $5.64 / 54.2$ & $18.18 \pm 4$ & $109.8 \pm 36.15$ & 6.04 & $\mathrm{P}<0.05$ \\
\hline 6 & $5.74 / 54.2$ & $57.23 \pm 9.97$ & $267.88 \pm 73.92$ & 4.68 & $\mathrm{P}<0.05$ \\
\hline 7 & $5.93 / 39.3$ & $45.82 \pm 9.81$ & $136.55 \pm 17.96$ & 2.98 & $\mathrm{P}<0.01$ \\
\hline 8 & $5.94 / 60.0$ & $21.42 \pm 6.4$ & $69.15 \pm 18.56$ & 3.23 & $\mathrm{P}<0.05$ \\
\hline 9 & $5.91 / 55.8$ & $3.65 \pm 0.88$ & $23.83 \pm 5.86$ & 6.53 & $\mathrm{P}<0.05$ \\
\hline 10 & $5.53 / 34.2$ & $3.1 \pm 0.68$ & $20.9 \pm 2.89$ & 6.74 & $\mathrm{P}<0.01$ \\
\hline
\end{tabular}

Lee ST, Huang MY and Wu TF. Investigation of Proteomic Responses and Copyright $($ Lee ST, Huang MY and Wu TF.

Anticancer Activities of an Isolated Strain of Cordyceps sinensis Under Different Nutritional Fermentation Conditions. J Microbiol Biotechnol, 2019, 4(1): 000137. 


\section{Open Access Journal of Microbiology \& Biotechnology}

\begin{tabular}{|c|c|c|c|c|c|}
\hline 11 & $5.45 / 34.0$ & $47.03 \pm 8.53$ & $120.92 \pm 12.07$ & 2.57 & $\mathrm{P}<0.01$ \\
\hline 12 & $5.96 / 11.6$ & $0.96 \pm 0.47$ & $11 \pm 3.74$ & 11.46 & $\mathrm{P}<0.05$ \\
\hline 14 & $5.58 / 26.8$ & $0.65 \pm 0.18$ & $10.78 \pm 2.31$ & 16.58 & $\mathrm{P}<0.01$ \\
\hline 15 & $5.22 / 31.7$ & $3.73 \pm 0.46$ & $14.9 \pm 1.65$ & 3.99 & $\mathrm{P}<0.01$ \\
\hline 16 & $5.91 / 66.0$ & $0.57 \pm 0.009$ & $12.9 \pm 4.32$ & 22.63 & $\mathrm{P}<0.05$ \\
\hline 17 & $5.36 / 34.0$ & $4.92 \pm 1.79$ & $105.43 \pm 27.81$ & 21.43 & $\mathrm{P}<0.05$ \\
\hline A & $4.82 / 12.6$ & $4.22 \pm 0.76$ & $0.32 \pm 0.2$ & -13.5 & $\mathrm{P}<0.01$ \\
\hline B & $4.37 / 14.8$ & $72.87 \pm 24.07$ & $43.32 \pm 17.8$ & -1.68 & $\mathrm{P}<0.05$ \\
\hline C & $4.69 / 28.8$ & $12.52 \pm 2.52$ & $0.75 \pm 0.27$ & -16.7 & $\mathrm{P}<0.01$ \\
\hline $\mathrm{D}$ & $4.96 / 27.0$ & $157.38 \pm 50.34$ & $3.03 \pm 0.75$ & -51.94 & $\mathrm{P}<0.05$ \\
\hline E & $4.78 / 26.8$ & $140.1 \pm 23.61$ & $2.9 \pm 0.75$ & -48.31 & $\mathrm{P}<0.01$ \\
\hline F & $5.74 / 30.7$ & $18.6 \pm 2.34$ & $2.92 \pm 0.79$ & -6.37 & $\mathrm{P}<0.05$ \\
\hline G & $5.42 / 44.5$ & $107.32 \pm 17.06$ & $15.2 \pm 2.07$ & -7.06 & $\mathrm{P}<0.01$ \\
\hline H & $5.12 / 50.8$ & $161.02 \pm 15.16$ & $96.92 \pm 21.64$ & -1.66 & $\mathrm{P}<0.01$ \\
\hline
\end{tabular}

Table 4: The differentially expressed protein spots between the mycelia grown in glucose and lactose media.

The identifications of the differentially expressed proteins were not feasible because the genome annotation of Paecilomyces farinosus is not available in the protein database. However, relying on the principle of gene sequence conservation across species, three abundant differentially expressed protein spots (spots 1 , 11 and 17) in the mycelia in the lactose media were tried to be identified using liquid chromatography tandem mass spectrometry (LC-MS/MS) and TurboSequest software. No significant hits were acquired for the protein spots 1 and 17. Nevertheless, the de novo sequencing was performed to interpret the peptide sequences of two proteins (Figure 3). Two peptides of the protein spot 11 were identified to be related to the aldehyde dehydrogenase of Alternaria alternata (alternaria rot fungus).
Spot 1

AQATWPMPGVQVK
AQAQGTPMPGVQAR
WQQFNEYAFK
PLLGATLDGR
QAGVNQMGRDGR
QGAVNQ
MGRLSK
HWQEPVK
VATVLEPAR
TAVLAHFVQAR
HVTVATLVQVK
EHFEMR
AFAEFHVK
MVGV
TNGPGK
GNLQMYLR
GTWLPR

PFPVNTARK

SLDDNTAQR

LGQYFCQDFYQR

HSNSLSHAR

SLTVK

PAHLLNGR

MTWLVTK

TVYMLFNQAR

DLTWPPILAAK

VCGPQSGWGDTR

MQGPESGWGNEK

LGGDQQFAR

FDQELGELVPAR

SFLGK

PLQEHSALTSFLGK

MESHVHTYEACHR
Spot 17

FELSTK

VSLMTR

PSDLTK

VSDWR

SSTLLHSGR

ETLLHATK

DGTLLHSGR

ETLLHATK

TAAFFPDFQK

DWQLCDLAR

VQQNLATAK

TQQNLSQR

VAQPPDQTVFAFEK

AEPPLMVTTDFTR

ATWPLR

ATWTHK

QFYPSQK

QSEHLQR

AEVPLQAFSLFK

FNSELQWVDHR

LNAVLSHGLVFDFK

QHLLSHGLTESYR

GHLLDVNQGDEK

GHNLLTLQGDTR

MTVFQSVSGHR

HPVTVYADVPLK

YLPGGNTAR

NGAVLSLRVK

MWQPAPLHAR
EVFQLGMTK

VQLLQVTFANLLFR

PPDRQETEQNLQCK

PAHLDVVK

GTLHPNGR

LVPHISGR

PLQCDHAGGCLHHK

PNWVNHAGNGCFVR

SCGMQLLSGWGNTR

GSCHLISGWGLEK

VGMLTGQLVQEEFVK

LLTGQIVEEQFAR

WTDMPDAAEK

GLHTYTVPAATR

MGTQAFGSTR

VAMADGDTK

PDNYFMTPDGTFK

NASRHHSNLLFR

GQFESGLEYMK

LAEFCPEY

QEFRGVAMYMK

DNHQGFFHGPHGWR

TDHDWFFHGPHDRK

YEPVEWMQNK

GYMAFQPHGSR

AQPALAFYGFEQQA

LNPNFLMDGFE

FMGDYDSHPPLFR

YLVPSPPYEFLK

CLQSSPPYEMTR

Figure 3: The de novo sequencing of the differentially expressed protein spots 1 and 11 in the mycelia in the lactose media. 


\section{The Anticancer Activities of the G308-1 Strain Vrown in various Liquid Media}

The proteomic responses of the G308-1 strain in various liquid media suggested that the G308-1 strain might adopt a corresponding proteome in response to a specific carbon source. This response, in turn, might elicit a specific array of bio-products including primary and secondary metabolites which are synthesized in the mycelia and possibly relevant to the anticancer activities of the fungi. In order to examine the anticancer activities of the G308-1 strain cultured under various nutritional conditions the water or ethanol extracts of the G308-1 strain cultivated in the glucose, sucrose, maltose or lactose media were explored for their abilities to suppress the HepG2, Du145, Hela and MCF-7 cells. The preliminary results demonstrated that the water extracts had the best inhibitory results to the cancer cells when the extracts were made by incubating the mycelia with the $60^{\circ} \mathrm{C}$ water at $1: 10$ ratio $(\mathrm{v} / \mathrm{v})$ (data not shown). As illustrated in Figure 4, the suppressive effects augmented essentially with the increasing concentrations of the water extracts [0.03\% to $3 \%(\mathrm{v} / \mathrm{v})]$ when each cancer cell line was treated with each water extract. Hela and Du 145 cells were more sensitive to the water extracts than HepG2 and MCF-7 cells at all the applied concentrations in terms of each water extract. At low concentrations $0.03 \%$ to $0.3 \%$ ) the HepG2 and MCF-7 cells were barely harmed by each water extract. However, high concentrations $(1 \%$ and $3 \%$ ) of each water extract showed the repressive impacts nearly on all the cell lines. At high concentrations the water extracts made from the mycelia in the lactose media had better inhibitory results to the HepG2 cells than those from the other three media. Figure 5 demonstrated all the cell lines were essentially insensitive to low concentrations of the ethanol extracts made from the mycelia in glucose, sucrose or maltose. However, at low concentrations the ethanol extracts produced from the mycelia in the lactose media exerted the better inhibitory activities to the Du145, Hela and MCF-7 cells. In contrast to low concentrations, high concentrations of each ethanol extract showed much stronger suppressive influences on all the cell lines. Except for the HepG2 cell at high concentrations there were no significant differences between the efficacies of all four ethanol extracts for each cell line (Figure 5). The ethanol extracts produced from the mycelia in the lactose media showed much better repressive activities to the HepG2 cell than those from the other three media (Figures 4 and 5). In addition, the HepG2 cells were only inhibited by the highest concentration of each ethanol extract.
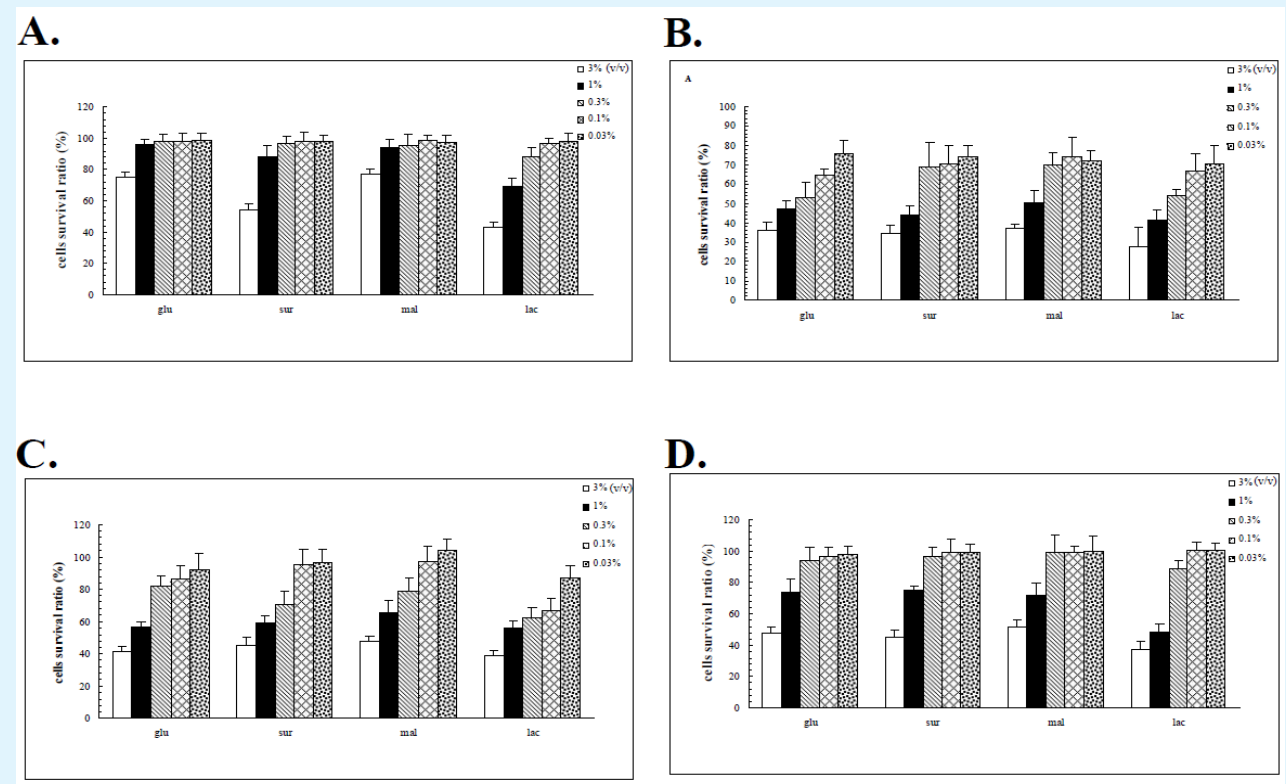

Figure 4: The anticancer activities of the aqueous extracts of the mycelia grown in the glucose, sucrose, maltose and lactose media to the HepG2, Du145, Hela and MCF-7 cells. (A) HepG2 cell. (B) Du145 cell. (C) Hela cell. (D) MCF-7 cell. Each cell was treated with the water extracts from $3 \%(\mathrm{v} / \mathrm{v})$ to $0.3 \%(\mathrm{v} / \mathrm{v})$ for 72 hours as described in Material and Methods. Each diagram was the representative data of three independent experiments with the triplicate assay for each measurement. glu: the 25 extracts from the mycelia grown in the glucose medium. sur: the extracts from the sucrose medium. mal: the extracts from the maltose medium. lac: the extracts from the lactose medium. 


\section{Open Access Journal of Microbiology \& Biotechnology}

A.

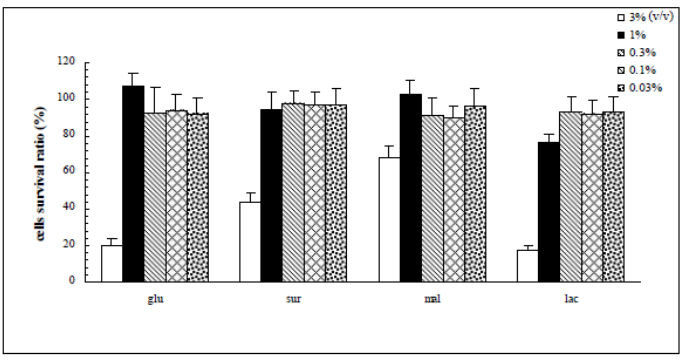

C.

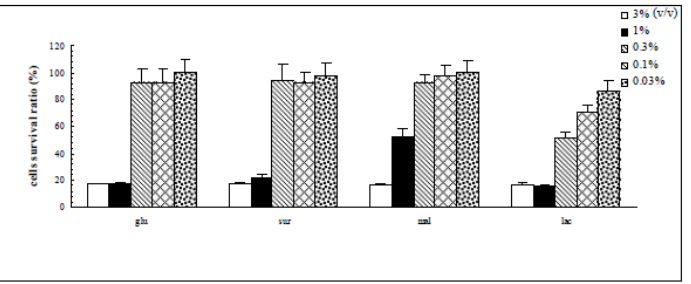

B.

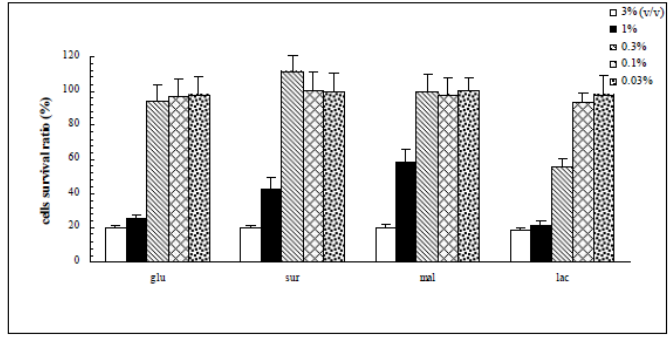

D.

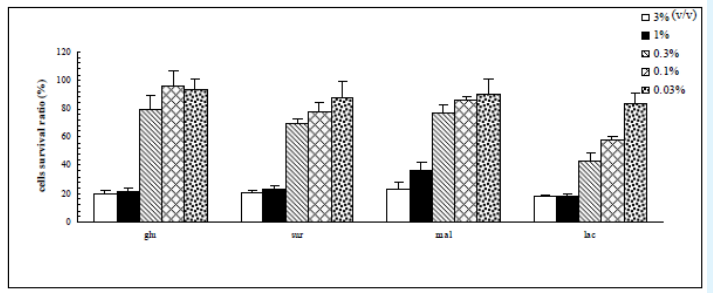

Figure 5: The anticancer activities of the ethanol extracts of the mycelia grown in the glucose, sucrose, maltose and lactose media to the HepG2, Du145, Hela and MCF-7 cells. (A) HepG2 cell. (B) Du145 cell. (C) Hela cell. (D) MCF-7 cell. Each cell was treated with the ethanol extracts from $3 \%(\mathrm{v} / \mathrm{v})$ to $0.3 \%(\mathrm{v} / \mathrm{v})$ for 72 hours as described in Material and Methods. Each diagram was the representative data of three independent experiments with the triplicate assay for each measurement.

\section{Discussion}

The fungus strain utilized in this study was isolated in Yunnan province of People Republic of China and identified as Paecilomyces farinosus. Although the link of Paecilomyces farinosus to the anamorph of $C$. sinensis is still under controversy, $P$. farinosus possesses the pharmacological activities $[23,24]$.

To gain insight into the biological effects of various carbon sources and to evaluate the proteome profile changes evoked by cell's adaptation to the different nutritional conditions, two-dimensional gel electrophoreses were utilized to monitor the proteome changes of a Paecilomyces farinosus strain (G308-1 strain) cultivated in liquid media containing glucose, sucrose, maltose and lactose. Because glucose is the best carbon source for the fungi, the proteomes of the mycelia cultivated in the liquid media containing glucose were compared with those of the mycelia in the sucrose, maltose or lactose media. The comparative results demonstrated that some proteins were induced or repressed under the different nutritional conditions (Tables 2-4). The most proteome profile change was elicited in the mycelia in the lactose media with 17 downregulated and 8 up-regulated proteins (Table 4).
However, much fewer differentially expressed proteins (eight and eight) were found in the mycelia derived from the sucrose and maltose media (Tables 2 and 3). Consistent with this result, Trabalzini, et al. (2003) [15] reported that 54 proteins are up-regulated and 138 proteins are down-regulated during the physiological fermentation stress under which glucose concentration gradually decreases in the YPD media. The dramatic proteome profile change induced by the lactose media suggested that the fungi might adopt a more complicated metabolic pathway to metabolize the lactose. In contrast, it might be easier for the fungi to metabolize the sucrose and maltose. In this study, the G308-1 strain at exponential stage was utilized for the proteomic analyses and therefore the proteome profile change was not due to the physiological fermentation stress.

The proteomic comparisons of the G308-1 strain in various nutritional media indicated that a specific carbon source might induce a corresponding proteome in the mycelia and probably, in turn, a specific array of bioproducts which likely contribute to the anticancer activities of the fungi. The anticancer results demonstrated that the water extracts showed the selectivity to Hela and Du 145 cells and for HepG2 cells at high concentrations the water extracts made from the 


\section{Open Access Journal of Microbiology \& Biotechnology}

mycelia in the lactose media had better suppressive effects (Figure 4). As to the ethanol extract, all the cell lines were almost insensitive to low concentrations of the extracts but high concentrations of the extracts showed much stronger inhibitory abilities. Conclusively the ethanol extracts prepared from the mycelia in the lactose media showed much better inhibitory activities to each cell line than those from the other three media (Figure 5). The above results implicated that the water or ethanol extracts of the G308-1 strain showed the selectivity to the cancer cell lines. In addition, the anticancer results might vary with the proteome profile changes which were evoked by a specific carbon source and probably resulted in the production of a different array of bio-products in the mycelia under the different nutritional conditions.

This study was the first paper that described the proteome changes of a fungus induced by the different nutritional conditions. If the differentially expressed proteins could be identified in the time when the genome annotations of fungi are available in the protein database, the metabolic pathways adopted in response to a specific carbon source can be interpreted. Therefore, relying upon the interpreted metabolic pathway, the metabolites correlated with the pharmacological activities may be predicted. In addition, the metabolic pathways may be changed genetically using various molecular biological tools to improve the production of the metabolites.

\section{Conflict of Interest Disclosure}

The authors declare that there is no conflict of interest regarding the publication of this paper

\section{Funding Acknowledgement}

This work was supported by from the Ministry of Science and Technology of Taiwan (grant number MOST 105-2320-B-218-001-MY3).

\section{References}

1. Chen GZ, Chen GL, Sun T, Hsieh GC, Henshall JM (1991) Effects of Cordyceps sinensis on murine $T$ lymphocyte subsets. Chin Med J (Engl) 104(1): 4-8.

2. Zhang Z, Xia SS (1990) Cordyceps Sinensis-I as an immunosuppressant in heterotopic heart allograft model in rats. J Tongji Med Univ 10(2): 100-103.

3. Zhu JS, Halpern GM, Jones K (1998) The scientific rediscovery of a precious ancient Chinese herbal regimen: Cordyceps sinensis: part II. J Altern Complement Med 4(4): 429-457.
4. Kuo YC, Tsai WJ, Shiao MS, Chen CF, Lin CY (1996) Cordyceps sinensis as an immunomodulatory agent. Am J Chin Med 24(2): 111-125.

5. Feng MG, Zhou QG, Feng GH (1987) Vasodilating effect of cultured Cordyceps sinensis (Berk) Sacc. mycelia in anesthetized dogs. Zhong Yao Tong Bao 12(12): 41-45.

6. Shiao MS, Wang ZN, Lin LJ, Lien JY, Wang JJ (1994) Profiles of nucleosides and nitrogen bases in Chinese medicinal fungus Cordyceps sinensis and related species. Botanical Bulletin of Academia Sinica 35(4): 261-267.

7. Manabe N, Sugimoto M, Azuma Y, Taketomo N, Yamashita A, et al. (1996) Effects of the mycelial extract of cultured Cordyceps sinensis on in vivo hepatic energy metabolism in the mouse. Jpn J Pharmacol 70(1): 85-88.

8. Zhao X, Li L (1993) Cordyceps sinensis in protection of the kidney from cyclosporine A nephrotoxicity. Chin Med J 73(7): 410-412.

9. Yamaguchi $Y$, Kagota S, Nakamura K, Shinozuka K, Kunitomo M (2000) Antioxidant activity of the extracts from fruiting bodies of cultured Cordyceps sinensis. Phytother Res 14(8): 647-649.

10. Li SP, Li P, Dong TT,Tsim KW (2001) Anti-oxidation activity of different types of natural Cordyceps sinensis and cultured Cordyceps mycelia. Phytomedicine 8(3): 207-212.

11. Buenz EJ, Bauer BA, Osmundson TW, Motley TJ (2005) The traditional Chinese medicine Cordyceps sinensis and its effects on apoptotic homeostasis. J Ethnopharmacol 96(1-2): 19-29.

12. Bok JW, Lermer L, Chilton J, Klingeman HG, Towers GH (1999) Antitumor sterols from the mycelia of Cordyceps sinensis. Phytochemistry 51(7): 891-898.

13. Yang LY, Huang WJ, Hsieh HG, Lin CY (2003) H1-A extracted from Cordyceps sinensis suppresses the proliferation of human mesangial cells and promotes apoptosis, probably by inhibiting the tyrosine phosphorylation of Bcl-2 and Bcl-XL. J Lab Clin Med 141(1): 74-83.

14. Kolkman A, Olsthoorn MM, Heeremans CE, Heck AJ, Slijper M (2005) Comparative proteome analysis of 
Saccharomyces cerevisiae grown in chemostat cultures limited for glucose or ethanol. Mol Cell Proteomics. 4(1): 1-11.

15. Trabalzini L, Paffetti A, Scaloni A, Talamo F, Ferro E et al. (2003) Proteomic response to physiological fermentation stresses in a wild-type wine strain of Saccharomyces cerevisiae. Biochem J 370(1): 35-46.

16. Vido K, Spector D, Lagniel G, Lopez S, Toledano MB, et al. (2001) A proteome analysis of the cadmium response in Saccharomyces cerevisiae. J Biol Chem. 276(11): 8469-8474.

17. Bro C, Regenberg B, Lagniel G, Labarre J, MonteroLomeli M, Nielsen, J (2003) Transcriptional, proteomic, and metabolic responses to lithium in galactose-grown yeast cells. J Biol Chem 278(34): 32141-32149.

18. Godon C, Lagniel G, Lee J, Buhler JM, Kieffer S, et al. (1998) The H2O2 stimulon in Saccharomyces cerevisiae. J Biol Chem 273(35): 22480-22489.

19. de Nobel H, Lawrie L, Brul S, Klis F, Davis M, et al. (2001) Parallel and comparative analysis of the proteome and transcriptome of sorbic acid-stressed Saccharomyces cerevisiae. Yeast 18(15): 1413-1428.
20. Han MJ, Lee SY (2003) Proteome profiling and its use in metabolic and cellular engineering. Proteomics 3(12): 2317-2324.

21. Chen YQ, Wang N, Qu LH, Li TH, Zhang WM (2001) Determination of the anamorph of Cordyceps sinensis inferred from the analysis of the ribosomal DNA internal transcribed spacers and 5.8S rDNA. Biochem Syst Ecol 29(6): 597-607.

22. Yan JX, Wait R, Berkelman T, Harry RA, Westbrook JA, et al. (2000) A modified silver staining protocol for visualization of proteins compatible with matrixassisted laser desorption/ionization and electrospray ionization-mass spectrometry. Electrophoresis 21(17): 3666-3672.

23. Lang G, Blunt JW, Cummings NJ, Cole AL, Munro MH (2005) Paecilosetin, a new bioactive fungal metabolite from a New Zealand isolate of Paecilomyces farinosus. J Nat Prod 68(5): 810-811.

24. Cheng Y, Schneider B, Riese U, Schubert B, Li Z, et al. (2004) Farinosones A-C, neurotrophic alkaloidal metabolites from the entomogenous deuteromycete Paecilomyces farinosus. J Nat Prod 67(11): 18541858. 